\title{
CDISC SDTM Lesion Complexity Terminology
}

National Cancer Institute

\section{Source}

National Cancer Institute. CDISC SDTM Lesion Complexity Terminology. NCI Thesaurus.

Code C101861.

Terminology associated with the lesion complexity codelist of the Clinical Data

Interchange Standards Consortium (CDISC) Study Data T abulation Model (SDT M). 